\title{
Heat Shock Protein 27 Is an Emerging Predictor of Contrast-Induced Acute Kidney Injury on Patients Subjected to Percutaneous Coronary Interventions
}

\author{
Andrzej Jaroszyński ${ }^{1,2, *}$, Tomasz Zaborowski ${ }^{3}$, Stanisław Głuszek ${ }^{1}$, Tomasz Zapolski ${ }^{4}{ }^{(D}$, \\ Marcin Sadowski ${ }^{1}{ }^{(D}$, Wojciech Załuska ${ }^{5}$, Anna Cedro ${ }^{6}{ }^{(D}$, Teresa Małecka-Massalska ${ }^{7}$ \\ and Wojciech Dąbrowski ${ }^{8}$ (D)
}

check for updates

Citation: Jaroszyński, A.;

Zaborowski, T.; Głuszek, S.; Zapolski,

T.; Sadowski, M.; Załuska, W.; Cedro,

A.; Małecka-Massalska, T.;

Dabrowski, W. Heat Shock Protein 27

Is an Emerging Predictor of

Contrast-Induced Acute Kidney

Injury on Patients Subjected to

Percutaneous Coronary Interventions.

Cells 2021, 10, 684. https://doi.org/

10.3390/cells10030684

Academic Editor: Alexander

E. Kabakov

Received: 16 February 2021

Accepted: 17 March 2021

Published: 19 March 2021

Publisher's Note: MDPI stays neutral with regard to jurisdictional claims in published maps and institutional affiliations.

Copyright: (c) 2021 by the authors. Licensee MDPI, Basel, Switzerland. This article is an open access article distributed under the terms and conditions of the Creative Commons Attribution (CC BY) license (https:/ / creativecommons.org/licenses/by/ $4.0 /)$.
1 Collegium Medicum, Jan Kochanowski University in Kielce, 25-317 Kielce, Poland; sgluszek@wp.pl (S.G.); msadowski@ujk.edu.pl (M.S.)

2 Department of Nephrology, Wojewódzki Szpital Zespolony in Kielce, 25-736 Kielce, Poland

3 Department of Family Medicine, Medical University of Lublin, 20-954 Lublin, Poland; tzaborowski@wp.pl

4 Department of Cardiology, Medical University of Lublin, 20-954 Lublin, Poland; zapolia@wp.pl

5 Department of Nephrology, Medical University of Lublin, 20-954 Lublin, Poland; wtzaluska2@poczta.onet.pl

6 The Institute of Public Health, Jan Kochanowski University in Kielce, 25-317 Kielce, Poland; aniacedro@op.pl

7 Department of Human Physiology, Medical University of Lublin, 20-080 Lublin, Poland; teresa.malecka-massalska@umlub.pl

8 Department of Anesthesiology and Intensive Care, Medical University of Lublin, 20-954 Lublin, Poland; w.dabrowski5@gmail.com

* Correspondence: jaroszynskiaj@interia.pl; Tel.: +48-604-968-724

Abstract: Contrast-induced acute kidney injury (CI-AKI) is a serious complication associated with considerable morbidity and mortality. Heat-shock protein 27 (HSP27) plays a role in the defense of the kidney tissue against various forms of cellular stress, including hypoxia and oxydative stress, both features associated with CI-AKI. The aim of our study was to evaluate a potential predictive value of HSP27 for CI-AKI in patients subjected to percutaneous coronary interventions (PCI). Included were 343 selected patients subjected to PCI. Exclusion criteria were conditions that potentially might influence HSP27 levels. HSP27 serum levels were evaluated prior to PCI, together with serum creatinine, the concentration of which was also evaluated twice at 48 and $72 \mathrm{~h}$ post PCI. CI-AKI was diagnosed in $9.3 \%$ of patients. Patients in whom CI-AKI was diagnosed were older $(p<0.001)$, were more often females $(p=0.021)$, had higher prevalence of diabetes $(p=0.011)$, hypotension during PCI $(p<0.001)$, albuminuria $(p=0.004)$ as well as multivessel disease $(p=0.002)$, received higher contrast volume $(p=0.006)$, more often received contrast volume $(\mathrm{CV})$ above the maximum allowed contrast dose (MACD) $(p<0.001)$, and had lower HSP27 level $(p<0.001)$. On multivariate analysis, CV > MACD (OR 1.23, $p=0.001$ ), number of diseased vessels (OR 1.27, $p=0.006$ ), and HSP27 (OR 0.81, $p=0.001$ ) remained independent predictors of CI-AKI. Low concentration of HSP27 is an emerging, strong and independent predictor of CI-AKI in patients subjected to PCI.

Keywords: heat shock protein 27; acute kidney injury; contrast-induced nephropathy; percutaneous coronary interventions

\section{Introduction}

Contrast-induced acute kidney injury (CI-AKI) following the use of iodine-based radiographic contrast media (RCM) for diagnostic as well as therapeutic procedures is the third common cause of hospital-acquired AKI. CI-AKI is a serious complication associated with considerable morbidity and mortality. The incidence of CI-AKI is significant, and $\mathrm{CI}-\mathrm{AKI}$ remains a concern for patients undergoing percutaneous coronary interventions (PCI) [1-4]. 
The mechanisms underlying the CI-AKI have not been completely understood. The growing evidence exists, however, that ischemia reperfusion injury (IRI), hypoxia, and increased oxidative stress play a significant role in the CI-AKI pathogenesis [1-3,5-7].

Heat-shock proteins (HSPs) are a protein superfamily whose presence is found in all cells of all organisms. HSPs are synthesized in response to various nociceptive factors and protect cells against different forms of cellular stress, including oxidative stress, as well as apoptosis. HSPs play an important role in the intra- or extracellular defense of the kidney tissue. Heat-shock protein 27 (HSP27) is a member of the small molecular weight HSP family. High levels of HSP27 are normally present in the renal medulla in response to conditions of hypoxia and oxydative stress. Evidence exists that HSP27 prevents injury and restores normal cellular function in the kidney following IRI [8-15]. The association between HSP27 and CI-AKI, however, has not been elucidated.

Owing to the role HSP27 plays in the kidneys and that IRI and oxidative stress are characteristic features of CI-AKI, we hypothesized that HSP27 levels might have a predictive value for CI-AKI risk in patients subjected to PCI.

\section{Methods}

\subsection{Study Population}

Included in the study were 343 selected patients subjected to PCI (168 women and 175 men), aged 50-70 years (mean $66.36 \pm 7.32$ ). The following exclusion criteria were applied: age $<50$ years and $>70$ years (to minimize the potential influence of age on HSP27 levels), eGFR $<45 \mathrm{~mL} / \mathrm{min}$, myocardial infarction during the last 3 months, left ventricular ejection fraction $(\mathrm{LVEF})<50 \%$, neoplasma, C-reactive protein $>10 \mathrm{mg} / \mathrm{dL}$ (to avoid the influence of chronic kidney disease, myocardial infarction, heart failure, neoplasma and inflammation on HSP27 concentrations), and thyroid diseases. Excluded were also patients who received renal toxic medicine or RCM for any reason during the previous 2 months. Owing to the fact that it was impossible to estimate population size meeting the criteria used in our study, the sample size calculation was not performed. Included were all available patients.

\subsection{Percutaneous Coronary Interventions}

Patients with stable angina pectoris were subjected to elective PCI based on indications determined by the result of coronary angiography, which was performed at least 2 months earlier (to minimize the influence of RCM during coronary angiography). PCI was performed using standard techniques by the operator who decided on the type of the stents used as well as the approach site. Nonionic, low-osmolality RCM was used in all cases. For the prevention of CI-AKI, isotonic saline was administered intravenously in all patients according to guidelines $(1.0-1.5 \mathrm{~mL} / \mathrm{kg} / \mathrm{h}$ started $12 \mathrm{~h}$ before $\mathrm{PCI}$ and continued up to $24 \mathrm{~h}$ after PCI) [16]. Maximum allowed contrast dose (MACD) was calculated for each patient using the following formula: [ $5 \mathrm{~mL}$ of contrast/ $\mathrm{kg}$ body weight (maximum $300 \mathrm{~mL})] /$ serum creatinine $(\mathrm{mg} / \mathrm{dL})$. Then, the number of patients who received contrast volume (CV) in the dose exceeding MACD was calculated. Hypotension was diagnosed when systolic blood pressure was $<80 \mathrm{mmHg}$ and/or the patient required the treatment with inotropes or saline infusion was needed when PCI was performed.

\subsection{Acute Kidney Injury Assessment}

Serum creatinine (SCr) was determined pre-PCI and then twice at 48 and $72 \mathrm{~h}$. CI-AKI was diagnosed using the change between peak $\mathrm{SCr}$ level and pre-PCI value. CI-AKI was defined and classified into 3 grades according to the Acute Kidney Injury Network (AKIN) criteria [17]. eGFR was calculated using the CKD-EPI formula.

\subsection{Clinical Data and Biochemical Measurements}

Commercially available ELISA kits (Invitrogen eBioscience Human HSP27 Platinum, Product Code 15541607) were used to determine serum contents of HSP27 according to the 
manufacturer's protocols. Baseline demographic, and laboratory as well as clinical data were also collected.

\subsection{Statistical Analysis}

Statistical analysis was performed using Statistica Version 10 as described in detail previously [14]. The statistical significance of the differences between pre- and post-PCI results were compared using Student's $t$-test or using the Mann-Whitney U-test, when appropriate. Linear regression analysis was performed using the Pearson or Spearman test, as appropriate. For CI-AKI risk factors analysis, patients were divided into two groups according to the presence of CI-AKI (CI-AKI group and non CI-AKI group). Univariate as well as multivariate logistic regression analysis was used to estimate odds ratio (OR) of associated risk factors for RCM-induced CI-AKI. Variables showing a $p$-value $<0.05$ in univariate analysis entered the model. The receiver operating characteristics curves (ROC) were performed to determine optimal cut-off points for HSP27 in predicting CIN. Probability values of $p<0.05$ were accepted as significant.

\section{Results}

\subsection{Baseline Characteristics}

Clinical characteristics of the studied patients are summarized in Table 1.

Table 1. Differences in baseline characteristic between patients with and without contrast-induced acute kidney injury (CI-AKI).

\begin{tabular}{|c|c|c|c|c|}
\hline Parameter & $\begin{array}{c}\text { All Patients } \\
n=343\end{array}$ & $\begin{array}{c}\text { CI-AKI } \\
n=32\end{array}$ & $\begin{array}{c}\text { Non CI-AKI } \\
n=311\end{array}$ & $p$ \\
\hline Age (years) & $66.36 \pm 7.32$ & $72.8 \pm 6.72$ & $64.4 \pm 6.95$ & $<0.001$ \\
\hline Female gender (\%) & 38.2 & 46.9 & 37.3 & 0.021 \\
\hline Prior MI (\%) & 25.9 & 27.3 & 25.8 & 0.496 \\
\hline Diabete smellitus (\%) & 48.0 & 63.4 & 45.1 & 0.011 \\
\hline Hypertension (\%) & 83.7 & 81.1 & 83.9 & 0.504 \\
\hline Smoking $(\%)$ & 18.1 & 17.8 & 18.2 & 0.687 \\
\hline $\mathrm{EF}(\%)$ & $54.83 \pm 5.33$ & $52.70 \pm 5.21$ & $55.14 \pm 5.56$ & 0.165 \\
\hline Hemoglobin $(\mathrm{g} / \mathrm{dL})$ & $11.68 \pm 1.09$ & $10.43 \pm 1.08$ & $11.98 \pm 1.02$ & 0.091 \\
\hline Total cholesterol (mg/dL) & $188.3 \pm 37.35$ & $188.2 \pm 35.15$ & $188.3 \pm 37.35$ & 0.674 \\
\hline LDL cholesterol (mg/dL) & $114.8 \pm 30.11$ & $116.2 \pm 29.19$ & $114.7 \pm 29.08$ & 0.544 \\
\hline HDL cholesterol (mg/dL) & $43.82 \pm 17.08$ & $43.41 \pm 16.89$ & $43.85 \pm 16.45$ & 0.715 \\
\hline Triglycerides (mg/dL) & $176.3 \pm 59.27$ & $170.2 \pm 59.03$ & $176.6 \pm 58.9$ & 0.314 \\
\hline Hypotension during PCI (\%) & 9.5 & 22.7 & 8.1 & $<0.001$ \\
\hline RCM volume (mL) & $179 \pm 58$ & $198 \pm 41$ & $175.2 \pm 52$ & 0.006 \\
\hline $\mathrm{CV}>\mathrm{MACD}(\%)$ & 20.1 & 28.1 & 19.4 & $<0.001$ \\
\hline Number of diseased vessels $(n)$ & $2.3 \pm 0.7$ & $2.6 \pm 0.8$ & $2.2 \pm 0.7$ & 0.002 \\
\hline $\mathrm{eGFR}\left(\mathrm{mL} / \mathrm{min} / 1.73 \mathrm{~m}^{2}\right)$ & $62.7 \pm 9.04$ & $59.9 \pm 8.31$ & $62.90 \pm 8.91$ & 0.114 \\
\hline Albuminuria (\%) & 18.1 & 25.0 & 17.7 & 0.004 \\
\hline HSP27 $(\mu \mathrm{g} / \mathrm{L})$ & $32.7 \pm 8.14$ & $21.19 \pm 7.87$ & $35.3 \pm 8.11$ & $<0.001$ \\
\hline ACE/ARB (\%) & 86.0 & 87.5 & 85.6 & 0.327 \\
\hline Beta blockers (\%) & 75.8 & 78.1 & 74.9 & 0.213 \\
\hline Statins (\%) & 82.2 & 81.3 & 82.90 & 0.614 \\
\hline Diuretics (\%) & 19.0 & 18.8 & 19.1 & 0.799 \\
\hline
\end{tabular}

Abbreviations: MI, myocardial infarction; EF, ejection fraction; PCI, percutaneous coronary interventions; RCM, radiographic contrast media; MACD, maximum allowed contrast dose; ACE/ARB, angiotensin-converting enzyme inhibitors/angiotensin receptor blockers; HSP27, heat shock protein 27. 


\subsection{The Influence of Radiographic Contrast Media on Serum Creatinine Levels}

RCM-induced SCr increase associated with PCI procedure was found in $207(60.4 \%)$ patients, in $61(17.8 \%)$ patients SCr was unchanged, whereas in $75(21.9 \%)$ Scr decreased post-PCI. CI-AKI was diagnosed in 32 (9.3\%) patients (grade 1 in 21, grade 2 in 8 patients, and grade 3 in 3 patients). Mean SCr increase in CI-AKI group was $0.51 \pm 0.39 \mathrm{mg} / \mathrm{dl}$. None of the CI-AKI patients required renal replacement treatment. CV > MACD was found in $20.1 \%$ of patients.

\subsection{Differences between Patients with and without CI-AKI}

Patients in whom CI-AKI was diagnosed were older $(p<0.001)$, were more often females $(p=0.021)$, had a higher prevalence of diabetes $(p=0.011)$, had hypotension during PCI $(p<0.001)$, albuminuria $(p=0.004)$, received CV > MACD $(p<0.001)$, had a higher number of diseased vessels $(p=0.002)$, higher RCM volume $(p=0.006)$, and had lower HSP27 level $(p<0.001)$ (Table 1$)$. No significant differences between CI-AKI and non CI-AKI groups were found in the prevalence of hypertension and prior myocardial infarction as well as smoking. Similarly, no differences were observed in lipids, medication and ejection fraction between CI-AKI and non CI-AKI groups. No difference was found in baseline eGFR between CI-AKI and non CI-AKI groups $(p=0.114)$. The correlation between eGFR and HSP27 was also not significant $(r=0.108 ; p=0.099)$.

\subsection{Univariate and Multivariate Analyses for the Prediction for CI-AKI}

Table 2 presents analyses for the prediction for CI-AKI. On univariate analysis, age (OR 1.21, $p<0.001$ ), female gender (OR 1.29, $p=0.021$ ), diabetes mellitus (OR 1.09, $p=0.016$ ), ejection fraction (OR 0.85, $p=0.009$ ), hemoglobin (OR 0.89, $p=0.022$ ), hypotension during PCI (OR 1.21, $p=0.013), \mathrm{CV}>\mathrm{MACD}$ (OR 1.37, $p<0.001)$, number of diseased vessels (OR 1.31, $p=0.006$ ), albuminuria (OR 1.11, $p=0.014$ ), and serum HSP27 (OR $0.78, p<0.001$ ) were predictors of CI-AKI. On multivariate analysis, CV > MACD (OR 1.23, $p=0.001$ ), number of diseased vessels (OR 1.27, $p=0.008$ ), and HSP27 (OR 0.81, $p=0.001)$ remained independent predictors of CI-AKI.

Table 2. Predictors of contrast-induced nephropathy.

\begin{tabular}{|c|c|c|c|c|}
\hline Parameter & $\begin{array}{c}\text { Univariate OR } \\
\quad(95 \% \mathrm{CI})\end{array}$ & $p$ & $\begin{array}{l}\text { Multivariate OR } \\
(95 \% \mathrm{CI})\end{array}$ & $p$ \\
\hline Age (years) & $1.31(1.07-1.1 .58)$ & $<0.001$ & $1.18(0.98-1.92)$ & 0.104 \\
\hline Female gender $(\%)$ & $1.26(0.98-2.17)$ & 0.021 & $1.23(0.79-2.31)$ & 0.113 \\
\hline Prior MI (\%) & $1.12(0.64-2.23)$ & 0.187 & & \\
\hline Diabete mellitus (\%) & $1.09(0.73-1.549$ & 0.016 & $1.11(0.63-1.83)$ & 0.247 \\
\hline Hypertension (\%) & $1.13(0.73-2.051)$ & 0.285 & & \\
\hline Smoking (\%) & $1.35(0.77-2.87)$ & 0.297 & & \\
\hline $\mathrm{EF}(\%)$ & $0.85(0.51-1.18)$ & 0.009 & $0.96(0.65-2.01)$ & 0.237 \\
\hline Hemoglobin (g/dL) & $0.89(0.74-1.43)$ & 0.022 & $0.88(0.62-2.41)$ & 0.211 \\
\hline Total cholesterol (mg/dL) & $1.09(0.78-2.67)$ & 0.477 & & \\
\hline LDL cholesterol (mg/dL) & $1.28(0.73-2.05)$ & 0.201 & & \\
\hline HDL cholesterol (mg/dL) & $0.91(0.69-1.57)$ & 0.286 & & \\
\hline Triglycerides (mg/dL) & $1.17(0.82-1.84)$ & 0.366 & & \\
\hline ACE/ARB (\%) & $1.02(0.45-2.04)$ & 0.527 & & \\
\hline Beta blockers (\%) & $0.97(0.54-2.36)$ & 0.525 & & \\
\hline Statins $(\%)$ & $0.92(0.56-2.11)$ & 0.218 & & \\
\hline
\end{tabular}


Table 2. Cont

\begin{tabular}{ccccc}
\hline Parameter & $\begin{array}{c}\text { Univariate OR } \\
\mathbf{( 9 5 \% ~ C I ) ~}\end{array}$ & $p$ & $\begin{array}{c}\text { Multivariate OR } \\
\mathbf{( 9 5 \% ~ C I ) ~}\end{array}$ & $p$ \\
\hline Diuretics (\%) & $1.03(0.44-2.11)$ & 0.233 & $1.08(0.69-3.02)$ & 0.171 \\
\hline Albuminuria (\%) & $1.11(0.86-2.01)$ & 0.014 & $1.18(0.93-2.57)$ & 0.089 \\
\hline Hypotension during PCI (\%) & $1.21(1.03-2.13)$ & 0.013 & $1.23(0.99-2.11)$ & 0.001 \\
\hline CV $>$ MACD $(\%)$ & $1.39(1.05-2.17)$ & $<0.001$ & $1.27(0.99-2.03)$ & 0.006 \\
\hline Number of diseased vessels $(n)$ & $1.33(1.03-2.18)$ & 0.004 & 0.189 & $0.01(0.51-1.37)$ \\
\hline
\end{tabular}

Abbreviations: MI, myocardial infarction; EF, ejection fraction; PCI, percutaneous coronary interventions; CV > MACD, contrast volume > maximum allowed contrast dose; ACE/ARB, angiotensin-converting enzyme inhibitors/angiotensin receptor blockers; HSP27, heat shock protein 27; OR, odds ratio; CI, confidence interval.

\subsection{ROC Analysis}

The ROC analysis of HSP27 as a predictor of the CI-AKI was performed. The analysis showed the AUC equal to 0.687 and the sensitivity/specificity equal to $0.687 / 0.614$. The cut-off point was $19.67 \mu \mathrm{g} / \mathrm{L}$. The ROC curves are presented in Figure 1.

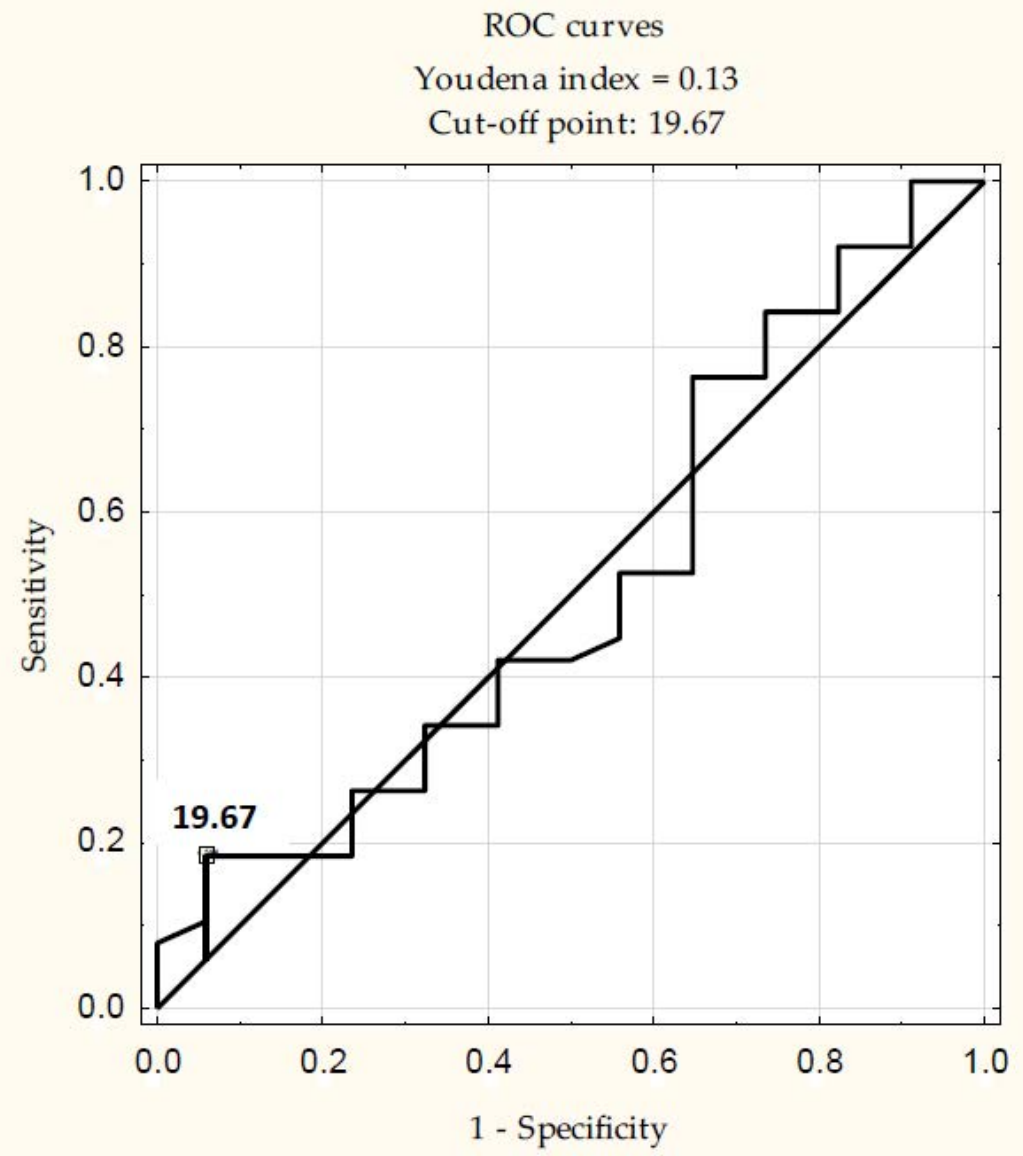

\begin{tabular}{|l|l|l|l|l|}
\hline & area & $95 \%$ CI & sens/spec $(\%)$ & cut-off \\
\hline HSP27 & 0.687 & $0.633-0.701$ & $0.687 / 0.614$ & 19.67 \\
\hline
\end{tabular}

Abbreviations: $\mathrm{CI}$, confidence interval; sens/spec - sensitivity/specificity.

Figure 1. Receiver operating characteristics (ROC) curve of heat-shock protein 27 (HSP27) in predicting CI-AKI. 


\section{Discussion}

The main finding of the current study is that low HSP27 level is a strong and independent predictor of CI-AKI in patients subjected to PCI. Additionally our study confirmed that the incidence of CI-AKI is significant even in relatively low-risk patients.

The incidence of CI-AKI due to PCI varies in a wide range depending on the diagnostic criteria, associated risk factors, concomitant diseases as well as applied prevention strategy $[7,18-20]$. In a large population of patients undergoing PCI, the incidence of CI-AKI was $7.1 \%$ in all-comers [1]; however, the risk increases to even $50 \%$ in patients with multiple risk factors [21]. In our study the incidence of CI-AKI was $9.3 \%$ and stage 1 of CIN was the most frequently observed degree of CI-AKI. Given that only stable patients were qualified to our study, the incidence of CI-AKI was relatively high compared to other results $[1,4]$. This may be due to the high prevalence of diabetes as well as patients with multivessel disease in the studied population. However, our results are similar to those obtained by Demir et al. [22], who used the same diagnostic criteria as well as prevention protocol.

To our knowledge this is the first study that revealed that low HSP27 serum levels predict CI-AKI in PCI patients. Mechanisms responsible for CI-AKI have not been fully elucidated; however, two mechanisms play a main role. After the initial increase in renal blood flow, the RCMs induce prolonged vasoconstriction, enchance vascular resistance and reduce renal blood flow, leading to hypoxia, increased oxidative stress, and ischemia reperfusion injury (IRI). Additionally, the RCMs exert direct toxic effects on both endothelial and tubular cells, finally resulting in cell damage, apoptosis, and cell death. Moreover, both processes can aggravate each other $[2,3,7,8]$.

Given that in the present study low HSP27 levels were associated with CI-AKI, we can speculate that HSP27 may exert a protective effect against CI-AKI. It is in agreement with previous reports on this issue. It has been demonstrated that HSPs, including HSP27, exert cytoprotective effects, interact with other proteins to facilitate normal cellular functions, take part in repairing proteins, target damaged protein for degradation, inhibit apoptosis, and exhibit antioxidant properties. HSP27 plays a crucial role in reducing the cell injury as well as protecting cells against different forms of cellular stress, including hypoxia and oxidative stress, both features associated with CI-AKI [6,13,23-28]. In physiological conditions HSP27 is present at the highest levels in renal medulla $[8,29]$. Even in normal conditions oxygen delivery to renal medulla is poor, thus vasoconstriction due to CI-AKI causes particularly severe consequences. It was demonstrated in animal models that acute ischemic kidney damage induces a 12-fold increase of HSP27 expression in the kidney tissues with a peak level observed $6 \mathrm{~h}$ post-reperfusion [12]. It suggests a protective role of HSP27 against hypoxia and oxidative stress [8-10,12,15,25]. The evidence exists that this chaperone protein inhibits apoptosis in IRI models [7]. Moreover, Kim et al. [29] demonstrated that HSP27 provides renal protection against IRI, whereas Fujigaki et al. showed that HSP27 prevents toxin-induced kidney injury [30]. Since HSP27 potentially prevents all main processes involved in CI-AKI pathogenesis, it can be hypothesized that low HSP27 serum levels may indirectly reflect low HSP27 concentrations in the kidney tissue, explaining our results. Further studies are required to confirm our results as well as to determine if serum HSP27 is only a marker of CI-AKI risk or whether it identifies more distinct mechanisms and can be a potential therapeutic target.

The present study has some important limitations. The first limitation is that our patients are selected. It limits factors that potentially influence HSP27 concentrations, but makes the study less generalizable. The second limitation is that our study is merely descriptive, and a pathophysiologic explanation for the relation between HSP27 and CIAKI needs to be part of further studies. Finally, given that it is a preliminary study, we evaluated HSP27 levels exclusively pre-PCI and it is likely that serial rather than single measurements of HSP27 may influence the results. 


\section{Conclusions}

Low concentration of HSP27 is an emerging, strong and independent predictor of CI-AKI in patients subjected to PCI.

Author Contributions: Conceptualization, A.J., W.Z., T.M.-M., and W.D.; methodology, T.Z. (Tomasz Zaborowski)., M.S., A.C., T.Z. (Tomasz Zapolski), and A.J.; funding acquisition, S.G., W.D.; validation, S.G., W.Z., and T.Z. (Tomasz Zaborowski); formal analysis, M.S., T.Z. ( Tomasz Zapolski), and A.J.; investigation, A.C., M.S., T.Z. (Tomasz Zaborowski), and T.Z. (Tomasz Zapolski); resources, W.Z.; data curation, M.S., A.C.; writing-original draft preparation, A.J., W.D., and T.Z. (Tomasz Zapolski); writing-review and editing, T.Z. (Tomasz Zapolski), A.J., S.G., W.Z., and W.D.; visualization, M.S., A.C.; supervision, S.G, W.Z., and W.D. All authors have read and agreed to the published version of this manuscript.

Funding: Medical University of Lublin. Award number PW232. Recipient-Andrzej Jaroszyński. The project is supported under the program of the Minister of Science and Higher Education under the name "Regionel Initiative of Excellence" in 2019-2022, project number: 024/RID/2018/19, financing amount: 11,999,000.00 PLN.

Institutional Review Board Statement: The study was conducted in accordance with the Declaration of Helsinki and was approved by the Ethical Committee of Medical University of Lublin (KE0254/125/2015).

Informed Consent Statement: All patients gave written consent, and the study protocol has been approved by the research institute's committee on human research.

Data Availability: The data used to support the findings of this study are available from the corresponding author upon request.

Conflicts of Interest: The authors declare no conflict of interest.

\section{References}

1. Tsai, T.; Patel, U.; Chang, T.; Kennedy, K.; Masoudi, F.; Matheny, M.; Kosiborod, M.; Amin, A.; Messenger, J.; Rumsfeld, J.; et al. Contemporary incidence, predictors, and outcomes of acute kidney injury in patients undergoing percuta-neous coronary interventions: Insights from the NCDR Cath-PCI registry. JACC Cardio. Int. 2014, 7, 1-9. [CrossRef]

2. Andreucci, M.; Faga, T.; Pisani, A. Prevention of Contrast-Induced Nephropathy through a Knowledge of Its Pathogene-sis and Risk Factors. Sci. World J. 2014, 2014, 823169. [CrossRef]

3. Krasinski, Z.; Krasińska, B.; Olszewska, M.; Pawlaczyk, K. Acute Renal Failure/Acute Kidney Injury (AKI) Associated with Endovascular Procedures. Diagnostics 2020, 10, 274. [CrossRef]

4. Mamoulakis, C.; Tsarouhas, K.; Fragkiadoulaki, I.; Heretis, I.; Wilks, M.F.; Spandidos, D.A.; Tsitsimpikou, C.; Tsatsakis, A. Contrast-induced nephropathy: Basic concepts, pathophysiological implications and prevention strategies. Pharmacol. Ther. 2017, 180, 99-112. [CrossRef] [PubMed]

5. Gassanov, N.; Nia, A.M.; Caglayan, E.; Er, F. Remote Ischemic Preconditioning and Renoprotection: From Myth to a Novel Therapeutic Option? J. Am. Soc. Nephrol. 2013, 25, 216-224. [CrossRef]

6. Matsumoto, T.; Urushido, M.; Ide, H.; Ishihara, M.; Hamada-Ode, K.; Shimamura, Y.; Ogata, K.; Inoue, K.; Taniguchi, Y.; Taguchi, T.; et al. Small Heat Shock Protein Beta-1 (HSPB1) Is Upregulated and Regulates Autophagy and Apoptosis of Renal Tubular Cells in Acute Kidney Injury. PLoS ONE 2015, 10, e0126229. [CrossRef] [PubMed]

7. Pistolesi, V.; Regolisti, G.; Morabito, S.; Gandolfini, I.; Corrado, S.; Piotti, G.; Fiaccadori, E. Contrast medium induced acute kidney injury: A narrative review. J. Nephrol. 2018, 31, 797-812. [CrossRef]

8. Marquez, E.; Sadowski, E.; Reese, S.; Vidyasagar, A.; Artz, N.; Fain, S.; Jacobson, L.; Swain, W.; Djamali, A. Serum HSP27 is associated with medullary perfusion in kidney allografts. J. Nephrol. 2012, 25, 1075-1080. [CrossRef]

9. E Smoyer, W.; Ransom, R.; Harris, R.C.; Welsh, M.J.; Lutsch, G.; Benndorf, R. Ischemic acute renal failure induces differential expression of small heat shock proteins. J. Am. Soc. Nephrol. 2000, 11, 211-221.

10. Inia, J.A.; O'Brien, E.R. Role of Heat Shock Protein 27 in Modulating Atherosclerotic Inflammation. J. Cardiovasc. Transl. Res. 2021, 14, 3-12. [CrossRef] [PubMed]

11. Zhang, H.; Jia, K.; Sun, D.; Yang, M. Protective effect of HSP27 in atherosclerosis and coronary heart disease by inhibiting reactive oxygen species. J. Cell. Biochem. 2018, 120, 2859-2868. [CrossRef]

12. Guo, Q.; Du, X.; Zhao, Y.; Zhang, D.; Yue, L.; Wang, Z. Ischemic post conditioning prevents renal ischemia reperfusion injury through the induction of heat shock proteins in rats. Mol. Med. Rep. 2014, 10, 2875-2881. [CrossRef] [PubMed]

13. O'Neill, S.; Harrison, E.M.; Ross, J.A.; Wigmore, S.J.; Hughes, J. Heat-Shock Proteins and Acute Ischaemic Kidney Injury. Nephron 2014, 126, 167-174. [CrossRef] [PubMed] 
14. Jaroszyński, A.; Jaroszyńska, A.; Siebert, J.; Dabrowski, W.; Niedziałek, J.; Bednarek-Skublewska, A.; Zapolski, T.; Wysokiński, A.; Załuska, W.; Książek, A.; et al. The prognostic value of positive T-wave in lead aVR in hemodialy-sis patients. Clin. Exp. Nephrol. 2015, 19, 1157-1164. [CrossRef]

15. Martínez-Laorden, E.; Navarro-Zaragoza, J.; Milanés, M.V.; Laorden, M.L.; Almela, P. Cardiac Protective Role of Heat Shock Protein 27 in the Stress Induced by Drugs of Abuse. Int. J. Mol. Sci. 2020, 21, 3623. [CrossRef]

16. Levine, G.; Bates, E.; Blankenship, J.; Bailey, S.; Bittl, J.; Cercek, B.; Chambers, C.; Ellis, S.; Guyton, R.; Hollenberg, S.; et al. 2011 ACCF/AHA/SCAI Guideline for Percutaneous Coronary Intervention: A report of the American College of Car-diology Foundation/American Heart Association Task Force on Practice Guidelines and the Society for Cardiovascular Angiography and Interventions. Circulation 2011, 124, 574-651. [CrossRef]

17. Mehta, R.L.; A Kellum, J.; Shah, S.V.; A Molitoris, B.; Ronco, C.; Warnock, D.G.; Levin, A. Acute Kidney Injury Network: Report of an initiative to improve outcomes in acute kidney injury. Crit. Care 2007, 11, R31. [CrossRef] [PubMed]

18. Golshahi, J.; Nasri, H.; Gharipour, M. Contrast-induced nephropathy; A literature review. J. Nephropathol. 2014, 3, 51-56.

19. The ad-hoc Working Group of ERBP; Fliser, D.; Laville, M.; Covic, A.; Fouque, D.; Vanholder, R.; Juillard, L.; Van Biesen, W. A European Renal Best Practice (ERBP) position statement on the Kidney Disease Improving Global Outcomes (KDIGO) Clinical Practice Guidelines on Acute Kidney Injury: Part 1: Definitions, conservative management and contrast-induced nephropathy. Nephrol. Dial. Transplant. 2012, 27, 4263-4272. [CrossRef] [PubMed]

20. Negishi, Y.; Tanaka, A.; Ishii, H.; Takagi, K.; Inoue, Y.; Uemura, Y.; Umemoto, N.; Yoshioka, N.; Morishima, I.; Asano, H.; et al. Contrast-Induced Nephropathy and Long-Term Clinical Outcomes Following Percutaneous Coronary Intervention in Patients With Advanced Renal Dysfunction (Estimated Glomerular Filtration Rate $<30 \mathrm{~mL} / \mathrm{min} / 1.73 \mathrm{~m}^{2}$ ). Am. J. Cardiol. 2019, 123, 361-367.

21. Wu, R.; Kong, Y.; Yin, J.; Liang, R.; Lu, Z.; Wang, N.; Zhao, Q.; Zhou, Y.; Yan, C.; Wang, F.; et al. Antithrombin III is a Novel Predictor for Contrast Induced Nephropathy After Coronary Angiography. Kidney Blood Press. Res. 2018, 43, 170-180. [CrossRef]

22. Demir, O.; Lombardo, F.; Poletti, E.; Laricchia, A.; Beneduce, A.; Maccagni, D.; Slavich, M.; Giannini, F.; Carlino, M.; Margonato, A.; et al. Contrast-Induced Nephropathy After Percutaneous Coronary Intervention for Chronic Total Occlu-sion Versus Non-Occlusive Coronary Artery Disease. Am. J. Cardiol. 2018, 122, 1837-1842. [CrossRef] [PubMed]

23. Chebotareva, N.; Bobkova, I.; Shilov, E. Heat shock proteins and kidney disease: Perspectives of HSP therapy. Cell Stress Chaperones 2017, 22, 319-343. [CrossRef]

24. Tian, X.; Zhao, L.; Song, X.; Yan, Y.; Liu, N.; Li, T.; Yan, B.; Liu, B. HSP27 Inhibits Homocysteine-Induced Endothelial Apoptosis by Modulation of ROS Production and Mitochondrial Caspase-Dependent Apoptotic Pathway. BioMed Res. Int. 2016, $2016,1-9$. [CrossRef] [PubMed]

25. Zhang, P.; Lun, M.; Schworer, C.; Blasick, T.; Marker, K.; Jones, J.; Carey, D. Heat-shock protein expression is highly sen-sitive to ischemia reperfusion injury in rat kidneys. Ann. Clin. Lab. Sci. 2008, 38, 57-64. [PubMed]

26. Rodríguez-Iturbe, B.; Johnson, R.J. Heat shock proteins and cardiovascular disease. Physiol. Int. 2018, 105, 19-37. [CrossRef]

27. Bellamy, C.O.; O’Neill, S.; Ingman, T.G.; Wigmore, S.J.; Harrison, E.M. Differential expression of heat shock proteins in healthy and diseased human renal allografts. Ann. Transplant. 2013, 18, 550-557. [CrossRef]

28. Jaroszyński, A.; Jaroszyńska, A.; Zaborowski, T.; Drelich-Zbroja, A.; Zapolski, T.; Dąrowski, W. Serum heat shock pro-tein 27 levels predict cardiac mortality in hemodialysis patients. BMC Nephrol. 2018, 19, 359. [CrossRef]

29. Kim, M.; Park, S.; Kim, M.; Chen, S.; Gerthoffer, W.; D’Agati, V.; Lee, H. Selective renal over expression of human heat shock protein 27 reduces renal ischemia-reperfusion injury in mice. Am. J. Physiol. Renal Physiol. 2010, 299, 347-358. [CrossRef]

30. Fujigaki, Y.; Sun, Y.; Fujikura, T.; Sakao, Y.; Togawa, A.; Suzuki, H.; Yasuda, H.; Hishida, A. Immunohistochemical study of heat shock protein 27 with respekt to survival and regeneration of proximal tubular cells after uranylacetate-induced acute tubular injury in rats. Ren. Fail. 2010, 32, 119-125. [CrossRef] 